\title{
Diagnosis, treatment characteristics, and survival of women with breast cancer aged 65 and above: a hospital-based retrospective study
}

\author{
Mehtap Kartal ${ }^{1 *}$, Sabahat Tezcan ${ }^{2}$ and Tulay Canda ${ }^{3}$
}

\begin{abstract}
Background: Breast cancer incidence in women increases with age, while survival rates decrease. Studies interpret this result as meaning higher comorbidity, diagnosis at later stages of the disease, and less effective treatment in the elderly. The aim of this study is to evaluate the diagnosis and treatment characteristics of breast cancer and their effect on the survival of women aged 65 and above.

Methods: The data within the files of 1064 women with breast cancer, who were followed-up in Dokuz Eylul University Medical Faculty Hospital between 2000 and 2006, were reviewed retrospectively. The survival probabilities at years 1 and 5 were calculated by life table analysis. The Kaplan-Meier test was used for calculating mean survival time, and the differences between groups were evaluated by log-rank test. The backward elimination method was used for multivariate analysis, and a -2 log-likelihood ratio was used for comparison of different models.

Results: Of the patients, 25.3\% were aged 65 and above at the time of the diagnosis. Patients in this group had more comorbidities and were more likely to be diagnosed at advanced stages than younger patients. Additionally, they had lower rates of surgical treatment, chemotherapy or radiotherapy. One and 5-year survival probabilities among age groups were $96.1 \%$ and $84.5 \%$, respectively, for $<65$ years, $93.5 \%$ and $84.8 \%$, respectively, for $65-69$, $98.7 \%$ and $84.0 \%$, respectively, for $70-74$, and $85.5 \%$ and $59.6 \%$, respectively, for 75 years and above. In the multivariate model, age, clinical stage, and comorbidity were found to be negatively associated with the survival rate.

Conclusions: The survival of women with breast cancer aged 65 and above was affected negatively by age at diagnosis, clinical stage, and the presence of comorbidity. Early diagnosis also is very important for elderly women. Additionally, because of higher comorbidity, their evaluation and treatment should be planned by an interdisciplinary team.
\end{abstract}

Keywords: Aged, Women, Breast neoplasms, Survival

\section{Background}

It is known that breast cancer incidence is rather low before the age of $30(25$ in 100,000) and demonstrates a linear increase through the age of 80 , where it reaches a plateau (around 500 in 100,000). Age is the most important risk factor in breast cancer occurrence after gender. It is observed that the relative risk for breast cancer increases by 5.8 times in women aged 65 and

\footnotetext{
* Correspondence: mehtapkartal@gmail.com

'Family Medicine Department of Dokuz Eylul University, 35340, Inciralti Izmir, Turkey

Full list of author information is available at the end of the article
}

above compared with women below age 65 [1]. Projections by the United Nations have shown that breast cancer incidence is increasing rather rapidly among women aged 50 and above [2]. In Turkey, the prevalence of breast cancer based on records of women varies between 21.4 and 45.6 per 100,000 , placing this disease at the top in terms of frequency of occurrence [3]. It was seen that among 11,208 women with breast cancer registered to 13 breast centers in eight provinces, $40.7 \%$ were between 51 and 70 years of age and $8.2 \%$ were aged 70 and above [4].

\section{Ciomed Central}


It is known that the survival of women with breast cancer diagnosed at later ages is worse than that of younger women. In relation to this, cardiovascular diseases, preexisting cancer, diabetes mellitus and dementia are mentioned among those diseases that most frequently accompany breast cancer in the elderly. It has also been pointed out that these diseases increase the risk of death [5-7]. The reasons why survival is lower in the elderly while breast cancer in this age group displays less aggressive tumor characteristics compared with the young have been examined. Among the reported reasons are that the diagnosis occurs in later stages and that the elderly receive less surgical treatment, are insufficiently treated, and receive less radiotherapy following breast-conserving surgery and chemotherapy [7-11]. The fact that patients from older age groups do not participate in many randomized controlled studies that assess the effectiveness of chemotherapies has meant that the most appropriate treatment for the elderly is still being discussed [12].

When the survival probabilities of women were assessed by age, it was seen that all of the women aged 65 years and above who were diagnosed in stage 0 and 1 were alive at the end of 5 years, while their survival was between $83.9 \%$ and $87.8 \%$ in stage $2,41.5 \%$ and $57.8 \%$ in stage 3 , and $14.8 \%$ and $20.3 \%$ in stage 4 [13]. Among the factors that influence the survival of patients with breast cancer, histological grade and the presence of lymphovascular invasion (LVI), particularly for those with negative lymph node, are significant apart from clinical staging [14-17].

In light of previous studies, the aim of this study was to determine certain diagnostic and treatment characteristics of women with breast cancer aged 65 and above, and compare their overall survival time, survival probabilities, and factors that might influence their survival with women younger than 65 years of age.

\section{Methods}

The study included 1064 female patients who were followed up with a breast cancer diagnosis and/or treatment in Dokuz Eylul University Medical Faculty Hospital between January $1^{\text {st }}, 2000$ and December $31^{\text {st }}$, 2006. The data on the patients were obtained by examining the patient files, hospital information systems and pathological reports retrospectively. The study was completed after the final monitoring status of the patients determined on December $31^{\text {st }}, 2011$. Approval was obtained from Dokuz Eylul University Medical Faculty Hospital Ethics Committee.

Cox proportional hazards models were used to evaluate the associations of age, comorbidity, clinical stage, histological grade, lymphovascular invasion, recurrence and metastasis in the follow-up period with mortality. Survival status was censored at the date of last in-person contact noted patient files, hospital information systems or
December $31^{\text {st }}, 2011$. The duration from diagnosis to death was accepted as overall survival time. The ages of the patients were given as $<65,65-69,70-74$, $\geq 75$ years. Diseases included in comorbid conditions were cardiovascular diseases, pre-existing cancer, diabetes mellitus as they are

Table 1 Descriptive characteristics of women with breast cancer

\begin{tabular}{|c|c|c|c|}
\hline & & n & $\%$ \\
\hline \multirow[t]{4}{*}{ Age at the time of diagnosis $(n=1036)$} & $<65$ & 774 & 74.7 \\
\hline & $65-69$ & 102 & 9.8 \\
\hline & $70-74$ & 92 & 8.9 \\
\hline & $\geq 75$ & 68 & 6.6 \\
\hline \multirow[t]{7}{*}{ Year of diagnosis $(\mathrm{n}=1036)$} & 2000 & 147 & 14.2 \\
\hline & 2001 & 137 & 13.2 \\
\hline & 2002 & 131 & 12.6 \\
\hline & 2003 & 152 & 14.7 \\
\hline & 2004 & 143 & 13.8 \\
\hline & 2005 & 164 & 15.8 \\
\hline & 2006 & 162 & 15.6 \\
\hline \multirow[t]{2}{*}{ Comorbidity $(n=690)$} & No & 557 & 80.7 \\
\hline & Yes & 133 & 19.3 \\
\hline \multirow[t]{4}{*}{ Stage $(n=912)$} & 1 & 208 & 22.8 \\
\hline & 2 & 415 & 45.5 \\
\hline & 3 & 197 & 21.6 \\
\hline & 4 & 92 & 10.1 \\
\hline \multirow[t]{4}{*}{ Histology ( $n=1012)$} & Invasive ductal ca & 473 & 46.7 \\
\hline & Invasive lobular ca & 220 & 21.7 \\
\hline & Mixed & 182 & 18.0 \\
\hline & Others & 137 & 13.5 \\
\hline \multirow[t]{3}{*}{ Histologic grade $(n=745)$} & 1 & 119 & 16.0 \\
\hline & 2 & 338 & 45.3 \\
\hline & 3 & 288 & 38.7 \\
\hline \multirow[t]{2}{*}{ Lymphovascular invasion ( $\mathrm{n}=849$ ) } & No & 174 & 20.5 \\
\hline & Yes & 675 & 79.5 \\
\hline \multirow[t]{2}{*}{ Surgery $(n=1010)$} & No & 52 & 5.1 \\
\hline & Yes & 958 & 94.9 \\
\hline \multirow[t]{2}{*}{ Chemotherapy ( $n=824)$} & No & 187 & 22.7 \\
\hline & Yes & 637 & 77.3 \\
\hline \multirow[t]{2}{*}{ Radiotherapy (n=794) } & No & 28 & 3.5 \\
\hline & Yes & 766 & 96.5 \\
\hline \multirow[t]{2}{*}{ Hormonotherapy (n=703) } & No & 113 & 16.1 \\
\hline & Yes & 590 & 83.9 \\
\hline \multirow[t]{2}{*}{ Recurrence $(n=545)$} & No & 490 & 89.9 \\
\hline & Yes & 55 & 10.1 \\
\hline \multirow[t]{2}{*}{ Metastases $(n=608)$} & No & 415 & 68.3 \\
\hline & Yes & 193 & 31.7 \\
\hline
\end{tabular}


the diseases that most frequently accompany breast cancer in the elderly.

\section{Statistical analysis}

Categorical variables were presented with frequency and percentage distributions, while continuous variables were given with mean and standard deviation values.

The 5-year survival probabilities were calculated by life table analysis. The mean survival times were calculated with the Kaplan-Meier test, and the differences between groups were evaluated by the log-rank test. The prognostic values of all related variables were first assessed in univariate analyses. Then the variables that had significant association with the outcome were included in a multivariate Cox proportional hazard model using the backward elimination method, with -2 log-likelihood ratio values taken into consideration for comparison of different models. The proportional hazards assumption was checked with a $\log$ minus log plot for each variable in the model.

The data were analyzed with the SPSS 15.0 program. All reported $\mathrm{p}$ values are two-tailed and $\mathrm{p}<0.05$ was accepted as statistically significant.

Table 2 Some characteristics of women with breast cancer according to their age at the time of diagnosis

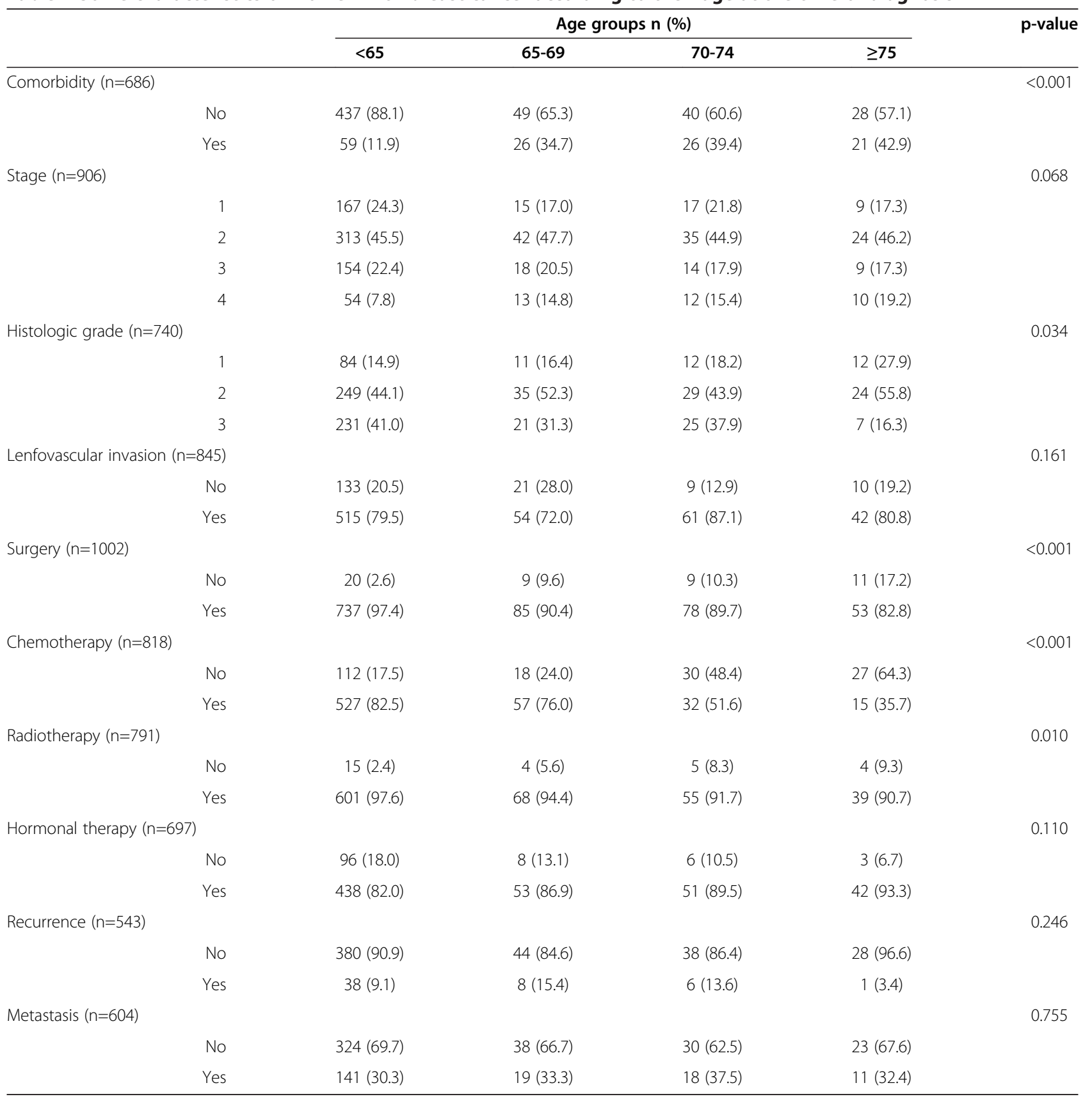


Table 3 Survival rates of women with breast cancer according to their age and stage at the time of diagnosis

\begin{tabular}{lccccc}
\hline & Stages & \multicolumn{4}{c}{ Age groups } \\
\cline { 3 - 6 } & & $\mathbf{< 6 5}$ & $\mathbf{6 5 - 6 9}$ & $\mathbf{7 0 - 7 4}$ & $\mathbf{2 7 5}$ \\
\hline \multirow{3}{*}{5 year survival* $^{*}$} & 1 & 98.0 & 91.7 & 94.1 & 75.2 \\
& 2 & 91.4 & 92.5 & 89.8 & 77.4 \\
& 3 & 72.5 & 81.0 & 72.5 & 37.5 \\
& 4 & 23.4 & 40.2 & 43.2 & 33.8 \\
\hline
\end{tabular}

*Life table analysis.

\section{Results}

The mean follow up period was $74.6 \pm 39.8$ months with a median of 77 months. Certain characteristics of the women included in the study are given in Table 1. Ages of the patients at the time of diagnosis ranges between
24 and 90 years, and $25.3 \%$ were aged $\geq 65$ years. The mean age of this subgroup was $71.9 \pm 5.4$ years at the time of the diagnosis.

The distribution of some characteristics of the patients in terms of age is summarized in Table 2. Women aged $>65$ years had more comorbid diseases than younger women $(\mathrm{p}<0.001)$. The clinical stages in which the women were diagnosed in terms of their ages were found not to be significantly different $(\mathrm{p}=0.068)$, with $19.2 \%$ of those $\geq 75$ years at clinical stage 4 at diagnosis. Patients aged $<65$ years received more surgical treatment (97.4\%), chemotherapy $(82.5 \%)$ and radiotherapy $(97.6 \%)$ than those who were older.

The mean survival times for the age groups were 121.0 months for the $<65$ years of age group, 119.0 months for the 65-69 years of age group, 121.4 months for the 70-

Table 4 Cox-regression models showing factors affecting the survival of women with breast cancer

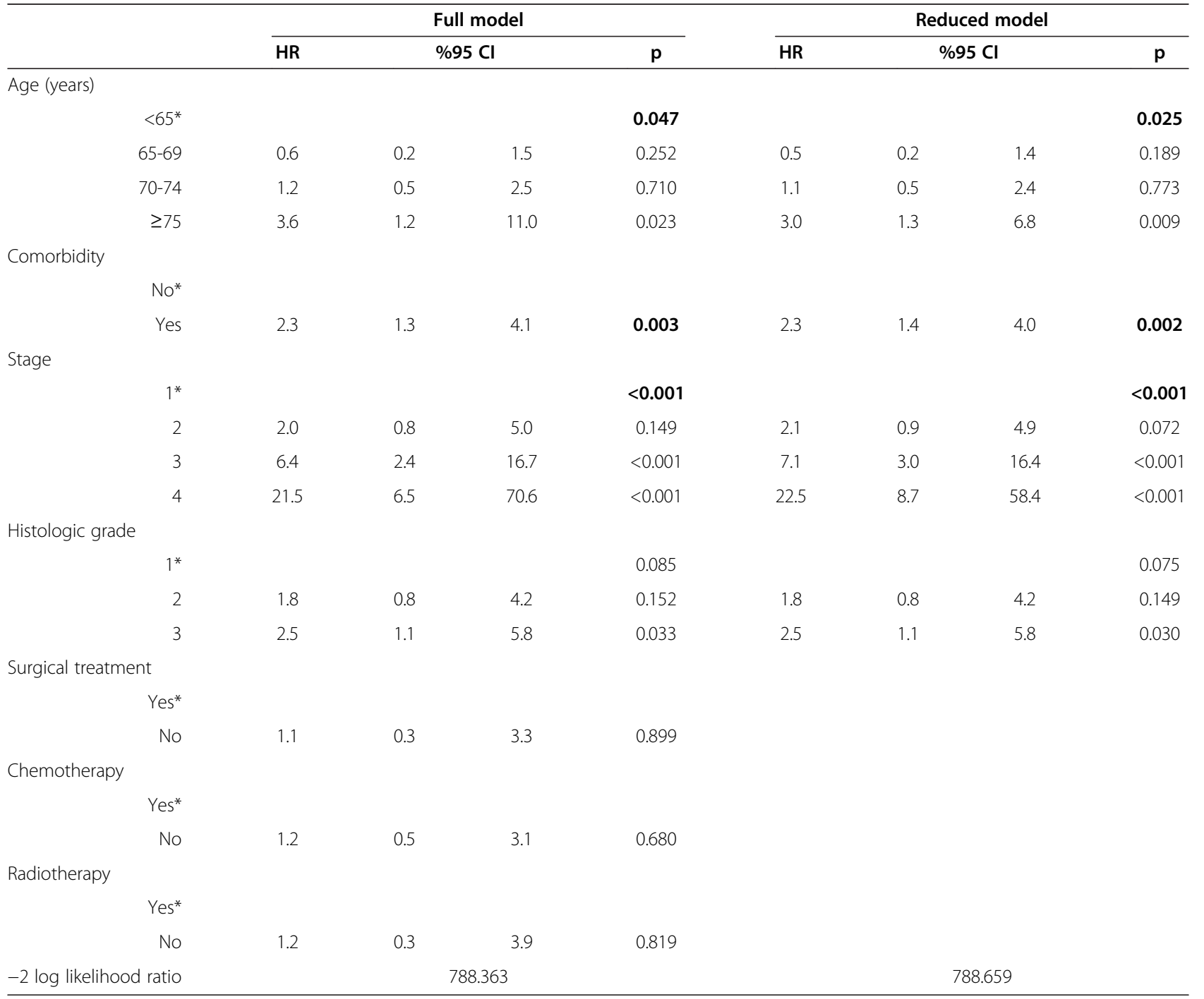


74 years of age group, and 85.2 months for the $\geq 75$ years of age group (median survival time $=86.0$ months) (Log rank chi-square=16.288; $\mathrm{p}<0.001$ ). The 5-year survival probabilities of patients in terms of age group were $84.5 \%$ for age $<65$ years, $84.8 \%$ for age $65-69$ years, $84.0 \%$ for age $70-74$ years, and $59.6 \%$ for age $\geq 75$ years. The survival probabilities by age group and clinical stage are given in Table 3.

In addition to age and clinical stage, the final model included co-morbid disease, histological grade, surgical treatment, chemotherapy and radiotherapy. These additional factors are shown to influence survival and be significantly different among groups. When all these variables were corrected in relation to one another but no variables were eliminated, age, clinical stage and comorbidity was found to be statistically significant $(p<0.05)$. The reduced model included age, clinical stage, comorbidity and histologic grade (Table 4 ). In the $\geq 75$ years of age group, increasing clinical stage and histologic grade, presence of comorbidity increased the hazard ratios (HR) of the patients. Presence of comorbidity increased the HR 2.3 times independently of the age at diagnosis, clinical stage and histological grade of the disease. When the survival curves of the reduced model are evaluated, the survival probabilities of the patients aged $<65$ years were found to be similar to 70-75 years of age group while 65-69 years of age group was better than both of them. And women over 75 years of age distinctly differ from younger women in all age groups which may be interpreted as age of 75 may be a breaking point for survival (Figure 1).

\section{Discussion}

The number of women with breast cancer increases with increase in life span and increase in elderly population, which in turn results in a higher increase in the number of elderly women with cancer. Breast cancer particularly affects elderly women in developed countries [9]. A multicentre study including 11,208 breast cancer patients from June 2005 until February 2008 showed that $8.2 \%$ were aged above 70 years, while in this study, patients aged above 65 years constituted $25.0 \%$ of all the patients [4]. The mean age of our patients above 65 years was 71.9 years, while another single-centered study including breast cancer patients aged above 65 years found the mean age of an equivalent group to be 72.7 years [18].

Co-morbid diseases accompanying breast cancer occur more frequently in elderly patients. It is known that in the elderly without any comorbid diseases, the disease displays a relatively good prognosis, whereas in those with comorbid diseases, it has rather a poor one. It was found in one study that comorbid disease increases the hazard ratio by 1.3 times independent of age, stage and treatment $[6,8]$. In our study, 34.2-44.4\% of women aged $\geq 65$ years have at least one disease accompanying breast cancer, while only $11.9 \%$ of those aged $\leq 65$ years have at least one co-morbid disease. In the multivariate analysis, co-morbid disease was found to increase the hazard ratio by 2.3 times.

Impairments in organ functions, which occur as a result of increased age as well as co-morbid diseases in the

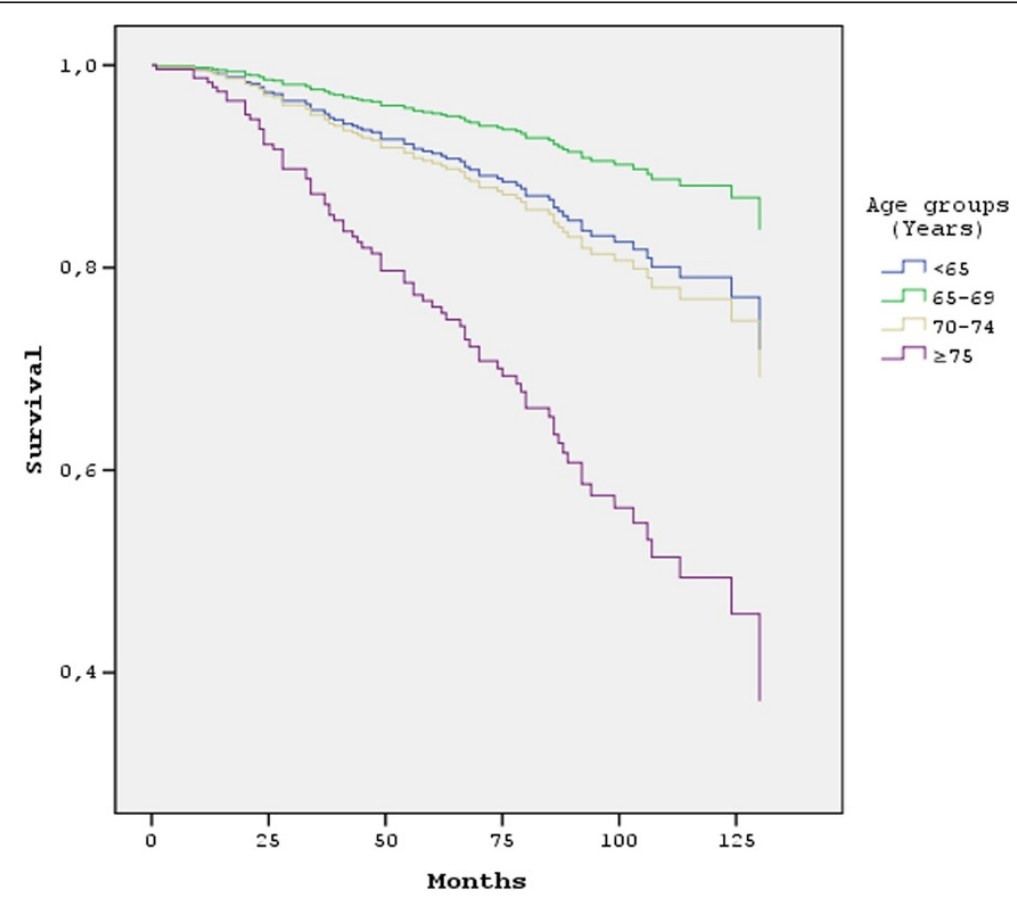

Figure 1 Survival curves of women with breast cancer according to their age at the time of diagnosis. 
elderly, might prevent the formulation of a management plan so that optimum treatment can be achieved. As a consequence, elderly patients cannot be treated in an aggressive way though they are diagnosed at later stages than younger patients $[9,19,20]$. When assessed from the viewpoint of surgical treatment, it has been reported that a more limited surgical treatment is administered in the elderly and that this situation is much more apparent in patients aged $\geq 80$ years [6]. It has been shown that breastconserving surgery is performed less often and that this situation continues even after recovery from the co-morbid disease is achieved [6-8]. The situation is similar with radiotherapy and chemotherapy. While in various studies patients aged $\geq 70$ and $\geq 80$ years are emphasized, the consensus is that the patients in this age group receive less chemotherapy and radiotherapy but more hormonal therapy $[6,7,19,20]$.

Even though it is known that patients are diagnosed later with more advanced age, it has been shown that this situation is also true for patients over 70 . While patients diagnosed at stage 4 constitute $3.7 \%$ of people aged $<65$ years, they constitute $8.5 \%$ of the age group $80-84[20,21]$. Similarly, we have also found in our study that women aged $\geq 75$ years could not benefit from improved staging methods and therapies. They were diagnosed at later stages which can be due to the gab in the screening programs or the ignorance of the disease and rejection of its hard treatment process by the elderly as these can easily affect their quality of life. They received less surgical treatment, chemotherapy and radiotherapy compared with patients in other age groups. This result might indicate that clinicians are caught between the short-term damage of special interventions in breast cancer and the death of patients due to other factors. Moreover, some studies indicate that breast cancer progresses less aggressively in the elderly and thus the usual treatment approaches are not required. However, the knowledge on this issue is limited and further research is needed $[9,18]$.

In the EUROCARE-3 study, the survival probabilities of women at 5 years were $76 \%$ for ages $65-74$ years and $69 \%$ for ages above 75 years [22]. In SEER records, on the other hand, survival at 5 years was $89.2 \%$ for women aged $\leq 65$ years, $90.4 \%$ for ages $65-74$ and $86.8 \%$ for ages above 75 years [23]. In a study conducted in Turkey, survival at 5 years for women aged $\geq 65$ years was $62 \%$. In the same study, stage and lymph node involvement were reported to be the most important factors affecting survival [18]. In our study, it was observed that survival probabilities at 5 years decrease with increased age, to $59.6 \%$ for ages above 75 years. When age and clinical stage, which affect the survival rate of patients with breast cancer, were evaluated together, the age of 75 appears to be a breaking point with markedly decreased survival rate.
In studies that assess the effect of the increasing inadequacies and deficiencies in treatment due to age on patient survival, different results were obtained; nevertheless, it has been shown that radiotherapy increased the overall and disease-free survival while this influence could not be confirmed for surgical treatment, radiotherapy and chemotherapy $[7,10]$. In the modeling made for this study, it can also be seen that the presence of co-morbid disease in addition to age and clinical stage influenced total survival significantly, whereas surgical treatment, radiotherapy and chemotherapy did not have any significant influence on overall survival.

The most important limitation of our study is that the data were collected retrospectively from existing patient files, which brings the limitations of recorded patient information, including certain shortcomings and possible mistakes.

\section{Conclusions}

In summary, women aged $\geq 65$ years were diagnosed with later stages of breast cancer. The co-morbid diseases of these patients might limit physician choices of treatment. Increased age, clinical stage and co-morbid diseases had a negative impact on survival. The early diagnosis of breast cancer is as important for the elderly as for the young and it will be essential to re-evaluate the upper age limit defined in national breast cancer screening programs. Furthermore, planning the post-diagnosis assessment and treatment of the functional losses and co-morbid diseases occurring with aging with an interdisciplinary team are important for the survival of patients.

\section{Competing interests}

The authors declare that they have no competing interests.

\section{Authors' contributions}

MK participated in the design and data collection of the study, performed the statistical analysis, and involved in drafting the manuscript. ST participated in the design of the study and involved in drafting and revising the manuscript. TC helped to draft the manuscript. The manuscript has been seen and approved by all authors.

\section{Author details}

${ }^{1}$ Family Medicine Department of Dokuz Eylul University, 35340, Inciralti Izmir, Turkey. ${ }^{2}$ Public Health Department of Hacettepe University, Ankara, Turkey. ${ }^{3}$ Pathology Department of Dokuz Eylul University, 35340, Inciralti Izmir, Turkey.

Received: 18 March 2013 Accepted: 26 August 2013

Published: 28 August 2013

\section{References}

1. Singletary SE: Rating the risk factors for breast cancer. Ann Surg 2003, 237:474-482

2. ESHRE Capri Workshop Group: Hormones and breast cancer. Hum Reprod Update 2004, 10:281-293.

3. Eser S, Yakut C, Özdemir R, Karakılınç H, Özalan S, Marshall SF, Karaoğlanoğlu O, Anbarcıoğlu Z, Üçüncü N, Akın Ü, Özen E, Özgül N, Anton-Culver H, Tuncer M: Cancer incidence rates in Turkey in 2006: a detailed registry based estimation. Asian Pac J Cancer Prev 2010, 11(Suppl6):1731-1739.

4. Özmen V: Breast cancer in the world and Turkey. J Breast Health 2008, 4:7-12. 
5. Louwman WJ, Janssen-Heijnen ML, Houterman S, Voogd AC, van der Sangen MJ, Nieuwenhuijzen GA, Coebergh JW: Less extensive treatment and inferior prognosis for breast cancer patient with comorbidity: a population-based study. Eur J Cancer 2005, 41(Suppl 5):779-785.

6. Hancke K, Denkinger MD, König JKurzeder C, Wöckel A, Herr D, Blettner M, Kreienberg R: Standard treatment of female patients with breast cancer decreases substantially for women aged 70 years and older: a German clinical cohort study. Ann Oncol 2010, 21(Suppl 4):748-753.

7. Lavelle K, Downing A, Thomas J, Lawrence G, Forman D, Oliver SE: Are lower rates of surgery amongst older women with breast cancer in the UK explained by co-morbidity? Br J Cancer 2012, 107(Suppl 7):1175-1180

8. Sanguinetti A, Estevan D, Lucchini R, Calzolari F, d'Ajello M, d'Ajello F, Avenia N: Treatment of elderly breast cancer patients in our breast unit [Abstract]. BMC Geriatr 2009, 9:A19.

9. Louwman WJ, Vulto JC, Verhoeven RH, Nieuwenhuijzen GA, Coebergh JW, Voogd AC: Clinical epidemiology of breast cancer in the elderly. Eur J Cancer 2007, 43(Suppl 15):2242-2252.

10. van de Water W, Bastiaannet E, Dekkers OM, de Craen AJ, Westendorp RG, Voogd AC, van de Velde $C J$, Liefers $G$ J: Adherence to treatment guidelines and survival in patients with early-stage breast cancer by age at diagnosis. Br J Surg 2012, 99(Suppl 6):813-820.

11. Wishart GC, Greenberg DC, Chou P, Brown CH, Duffy S, Purushotham AD: Treatment and survival in breast cancer in the Eastern Region of England. Ann Oncol 2010, 21(Suppl 2):291-296.

12. Scher KS, Hurria A: Under-representation of older adults in cancer registration trials: known problem, little progress. J Clin Oncol 2012, 30(Suppl 17):2036-2038.

13. Ries LAG, Milton PE: Patient and Tumor Characteristics. In SEER Sunvival Monograph: Cancer Survival Among Adults: U.S. SEER Program, 1988-2001. Edited by Gloeckler Ries LA, Young JL Jr, Keel GE, Eisner MP, Lin YD, Horner M-JD. Bethesda, MD: National Cancer Institute, SEER Program, NIH Pub. No. 07-6215; 2007:101-110.

14. Arriagada R, Le MG, Dunant A, Tubiana M, Contesso G: Twenty-five years of follow-up in patients with operable breast carcinoma: correlation between clinicopathologic factors and the risk of death in each 5-year period. Cancer 2006, 106(Suppl 4):743-750.

15. Ignatiadis M, Sotiriou C: Understanding the molecular basis of histologic grade. Pathobiology 2008, 75(Suppl 2):104-111.

16. Soerjomataram I, Louwman MW, Ribot JG, Roukema JA, Coebergh JW: An overview of prognostic factors for long-term survivors of breast cancer. Breast Cancer Res Treat 2008, 107:309-330.

17. Lee AH, Pinder SE, Macmillan RD, Mitchell M, Ellis IO, Elston CW, Blamey RW: Prognostic value of lymphovascular invasion in women with lymph node negative invasive breast carcinoma. Eur J Cancer 2006, 42(Suppl 3):357-362.

18. Selim S, Yasemin Benderli C: Yaşıı Meme Kanserli Hastalarda Tümör Özellikleri Tedavi Yaklaşımları ve Yașam Süreleri. Turk J Geriatr 2012, 15(Suppl 2):164-170.

19. Zappula E, Russo V, Gullota I, Patanè G, Trovato S, Lucifora B, Costa S, Tracia A, Caglià P, Amodeo C: Treatment of breast cancer in elderly patients [Abstract]. BMC Geriatr 2009, 9:A57.

20. Laki F, Kirova YM, Savignoni A, Campana F, Levu B, Estève M, Sigal-Zafrani B, Dorval T, Asselain B, Salmon RJ: Management of operable invasive breast cancer in women over the age of 70: long-term results of a large-scale single-institution experience. Ann Surg Oncol 2010, 17(Suppl 6):1530-1538.

21. Bastiaannet E, Liefers GJ, de Craen AJ, Kuppen PJ, van de Water W, Portielje JE, van der Geest LG, Janssen-Heijnen ML, Dekkers OM, van de Velde CJ, Westendorp RG: Breast cancer in elderly compared to younger patients in the Netherlands: stage at diagnosis, treatment and survival in 127,805 unselected patients. Breast Cancer Res Treat 2010, 124(Suppl 3):801-807.

22. Sant M, Aareleid T, Berrino F, Bielska Lasota M, Carli PM, Faivre J, Grosclaude P, Hédelin G, Matsuda T, Møller H, Möller T, Verdecchia A, Capocaccia R, Gatta G, Micheli A, Santaquilani M, Roazzi P, Lisi D, EUROCARE Working Group: EUROCARE-3: survival of cancer patients diagnosed 1990-94results and commentary. Ann Oncol 2003, 14((Suppl 5):v61-v118.
23. SEER Cancer Statistics Review, 1975-2009. Edited by Howlader N, Noone AM, Krapcho M, Neyman N, Aminou R, Altekruse SF, Kosary CL, Ruhl J, Tatalovich Z, Cho H, Mariotto A, Eisner MP, Lewis DR, Chen HS, Feuer E, Cronin KA. Bethesda, MD: (Vintage 2009 Populations), National Cancer Institute. http://seer.cancer.gov/ csr/1975_2009_pops09/browse_csr.php?section=4\&page=sect_04_table.14 html\#table 4.

doi:10.1186/1472-6874-13-34

Cite this article as: Kartal et al:: Diagnosis, treatment characteristics, and survival of women with breast cancer aged 65 and above: a hospitalbased retrospective study. BMC Women's Health 2013 13:34.

\section{Submit your next manuscript to BioMed Central and take full advantage of:}

- Convenient online submission

- Thorough peer review

- No space constraints or color figure charges

- Immediate publication on acceptance

- Inclusion in PubMed, CAS, Scopus and Google Scholar

- Research which is freely available for redistribution

Submit your manuscript at www.biomedcentral.com/submit
() Biomed Central 